Check for updates

Cite this: RSC Adv., 2017, 7, 23835

Received 15th March 2017

Accepted 14th April 2017

DOI: $10.1039 / \mathrm{c} 7 \mathrm{ra03065g}$

rsc.li/rsc-advances

\section{Corrosion wear characteristics of TC4, 316 stainless steel, and Monel K500 in artificial seawater}

\begin{abstract}
Chen Jun (D)*ab
The corrosion wear behaviors of TC4, 316 stainless steel, and Monel K500 in artificial seawater were systematically investigated in this study. The contribution of corrosion and wear on corrosion-wear synergism and damage-recovery process of passive film for the three alloys were addressed. It can be concluded that wear loss for these three alloys at cathodic polarization was lower than that anodic polarization and OCP. The passive film was damaged due to mechanical wear, resulting in low OCP and high corrosion rate. Electrochemical test showed that the passive film in the wear track area was only partially destroyed during the corrosion wear test. The ratio of the actual damage area in the wear track $S_{e} / S_{m}$ of 316 stainless steel and TC4 was much larger than that of Monel K500.
\end{abstract}

\section{Introduction}

Over the past few years, the corrosion wear behaviors of passive alloys was a research hotspot. Generally, typical passive alloys can form protective oxide film and maintain passivity in a corrosive solution. However, in many situations, these alloys were subjected to wear also, resulting in corrosion wear. In most cases, wear loss caused by corrosion wear was greater than the simple sum of the pure mechanical wear and pure corrosion. ${ }^{1-3}$ In general, various electrochemical methods have been performed to obtain electrochemical data on the corrosion-wear synergism and electrochemical reactions of alloys. The degradation of passive film can be evaluated through the change of corrosion potential or anodic current. ${ }^{4}$ Goldberg et al. ${ }^{5}$ have suggested an equation in which the repassivation current can be modeled and predicted by a single scratch test. Mischler et al. ${ }^{4,6,7}$ have proposed a model to calculate the average current per stroke during a reciprocating wear-accelerated corrosion test of passive metals by considering the real depassivated area. The concept of active wear track area was proposed by García ${ }^{8}$ as a way to investigate the mechanism of corrosion wear behaviors of passive materials under sliding conditions. The active wear track area indicated that a part of the wear track temporarily loses its passive characteristics due to mechanical interaction. Iwabuchi et al. $^{9-13}$ have studied the electrochemical factor in the corrosion wear of stainless steel and TC4 in a $\mathrm{Na}_{2} \mathrm{SO}_{4}$ solution. Moreover, they have considered the synergistic effect as dynamic corrosion. Olsson ${ }^{14,15}$ proposed an interesting approach, which made it to easy to obtain the values of the passive film thickness

${ }^{a}$ School of Materials Science and Engineering, Henan University of Science and Technology, 263, Kaiyuan Road, Luoyang 471023, Henan 471003, PR China. E-mail: chenjun318822200@163.com; Tel: +8615225508091

${ }^{b}$ Collaborative Innovation Center of Nonferrous Metals of Henan Province, Luoyang 471023, PR China with time during corrosion wear, without converting the charge densities. Using Olsson's model, Henry ${ }^{16,17}$ obtained values of film thickness of 316L stainless steel and TA6V4, in good agreement with the results obtained by XPS and EQCM, indicating that it is a powerful and interesting tool to determine the thickness and growth kinetics of the passive film.

Generally, stainless steel, Ti alloy, Ni alloy, Al alloy, and CoCrMo alloy have been frequently used for corrosion wear research due to their excellent corrosion resistance and good mechanical properties. ${ }^{718-23}$ Excellent corrosion resistance of these alloys was provided by spontaneous formation of oxide film on the metallic surface. ${ }^{16,17,24}$ Marine tribology has been developed in the recent years due to the increasing exploitation of ocean resources. The metal material, high polymer material, and nonmetal material are widely used in marine engineering equipment. A large number of metal materials are used in ships, oil gathering, offshore wind power generation devices, deep-sea drilling, underwater robots, underwater equipment, and other marine equipment. Ceramic materials have been used in marine lubricating ceramic bearings and friction pairs as well. Because seawater is corrosive, the resistance of marine equipment, especially the friction pairs, to corrosion and corrosive wear should be considered. In the present study, the selected alloys were TC4, 316 stainless steel, and Monel K500. Corrosion wear behaviors of these three alloys including corrosion-wear synergism, abrasion and electrochemical control mechanisms, and corrosion wear maps have been studied by many researchers. Various electrochemical methods mainly including open circuit potential, potentiodynamic polarization, polarization, and impedance were normally performed to provide essential information on corrosion evaluation. However, the damage-recovery process and destruction proportion of the passive film have not been fully explored. In the present study, the electrochemical and corrosion wear 
behaviors of TC4, 316 stainless steel, and Monel K500 were investigated. Specifically, the contribution of corrosion and wear to synergism and the destruction degree of the passive film were analyzed in detail.

\section{Experiments}

The corrosion wear test setup is illustrated in Fig. 1. This setup was combined with an in situ electrochemical measurement system. Sliding wear tests were carried out by a MMW-1 pin-ondisk tribometer manufactured by Jinan Testing Machine Manufacturing Company. A stationary ring was abraded by a rotating pin during sliding, with the rotation speed controlled by a computer data control system. Normal load was applied by a lever mechanism. Moreover, the friction coefficient was measured and obtained by an attached strain gauge. Electrochemical measurements were carried out using a CHI760C electrochemical workstation manufactured by $\mathrm{CHI}$ Instruments. The electrochemical cell was filled with about $300 \mathrm{~mL}$ artificial seawater. A saturated calomel electrode (SCE) was inserted into the cell close to the upper surface of the ring specimen to serve as a reference electrode, and a platinum wire was used as a counter electrode. All the potentials in this study are given with respect to the saturated calomel electrode (SCE).

The metallic materials used in the present study are TC4, 316 stainless steel, and Monel K500. Their chemical compositions are listed in Table 1 . The ring samples of metallic materials were machined into a size with an outer diameter of $54 \mathrm{~mm}$ and inner diameter of $38 \mathrm{~mm}$. Before carrying out the corrosion wear test, each metallic specimen was mechanically abraded using a series of SiC grinding papers up to 1500 grit, followed by cleaning in running water and acetone. Before being immersed into the electrochemical cell, all the surfaces except the upper surface of the ring were covered with paint for insulation. The area in contact with artificial seawater was about $11.5 \mathrm{~cm}^{2}$. A rotating alumina pin with a diameter of $4.7 \mathrm{~mm}$ was matched with a stationary metallic specimen. The wear track was a ring with

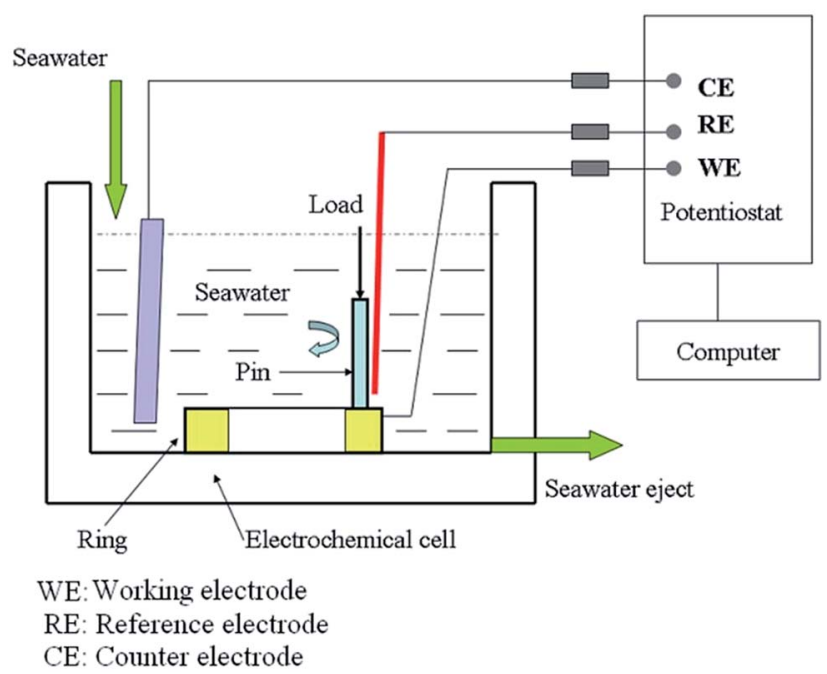

Table 1 Chemical composition (wt\%) of the three alloys

\begin{tabular}{llllll}
\hline TC4 & & \multicolumn{2}{l}{ Monel K500 } & \multicolumn{2}{l}{ 316 stainless steel } \\
\hline $\mathrm{Al}$ & 6.25 & $\mathrm{Cu}$ & 30 & $\mathrm{Cr}$ & 17.2 \\
$\mathrm{~V}$ & 4.21 & $\mathrm{Al}$ & 3 & $\mathrm{Ni}$ & 10.2 \\
$\mathrm{H}$ & 0.0073 & $\mathrm{Ti}$ & 0.6 & $\mathrm{Mo}$ & 2.1 \\
$\mathrm{O}$ & 0.19 & $\mathrm{Fe}$ & 1 & $\mathrm{C}$ & 0.04 \\
$\mathrm{Fe}$ & 0.22 & $\mathrm{C}$ & 0.1 & $\mathrm{~S}$ & $\leq 0.03$ \\
$\mathrm{Ti}$ & Balance & $\mathrm{Ni}$ & Balance & $\mathrm{Si}$ & $\leq 1$ \\
& & & & $\mathrm{Mn}$ & $\leq 2$ \\
& & & & $\mathrm{Fe}$ & Balance \\
\end{tabular}

a mean diameter of $46 \mathrm{~mm}$ and a width of $4.7 \mathrm{~mm}$ (diameter of the $\mathrm{Al}_{2} \mathrm{O}_{3}$ pin). The area of the wear track was $8 \mathrm{~cm}^{2}$. The corrosive solution in this study was artificial seawater, which was prepared according to the ASTM D1141-98 standard. In this study, the temperature of artificial seawater during experiment was maintained at $25^{\circ} \mathrm{C}$. The corrosion wear tests were carried out at the rotation speed of $200 \mathrm{rpm}$, which means the linear velocity was $0.54 \mathrm{~m} \mathrm{~s}^{-1}$. A normal load of $100 \mathrm{~N}$ was applied, corresponding to a nominal contact stress of about 1.5 MPa. This normal load was selected to generate a contact stress much smaller than the yield strength of the metallic materials to avoid plastic deformation. Sliding tests were conducted for $60 \mathrm{~min}$. After corrosion wear, ring specimens were ultrasonically cleaned with acetone. The gravimetric measurements were carried out using a TE214S-OCE analytical balance. Then, the volume loss of the metallic specimens could be obtained. The morphology of the worn surfaces was obtained using a JEM-5600LV scanning electron microscope (SEM). All the tests were repeated at least three times to check for reproducibility.

Several electrochemical measurements were conducted to investigate the effect of wear on corrosion. (1) Open circuit potential (OCP) variation curves were monitored before, during, and after corrosion wear. (2) Potentiodynamic polarization measurements, which involve measurement of the polarization curves of the metallic specimens under corrosion-only and corrosion wear conditions, were performed after attaining a stable OCP. The potential was swept from $-1 \mathrm{~V}$ to $+1 \mathrm{~V}$ at the sweep rate of $1.67 \mathrm{mV} \mathrm{s}^{-1}$. CHI software was used to analyze the polarization data. (3) During potentiostatic polarization measurement, a constant potential $E$ was imposed on the metallic specimen. The selected potential was maintained at a fixed value, and the current was measured as a function of time to follow the evolution of corrosion kinetics. (4) For simulating the damage and restoration process of the passive film and evaluating the destruction proportion of the passive film, potential pulse method (PPM) was applied. A constant cathodic potential $E$ was imposed on the metallic specimen to eliminate the passive film. Then, the potential was increased to a given value within $1 \mathrm{~ms}$. With the change of potential, the current rapidly increased and then exponentially decreased. This electrochemical variation was considered to simulate the exposure and recovery of the passive film. An example of the change in potential and current is shown in Fig. 2.

Fig. 1 The schematic of the corrosion wear apparatus. 


\section{Results and discussion}

\subsection{Electrochemical measurements}

OCP curves can be obtained by acquiring the potential difference of a working electrode and a reference electrode. The measured potential during the corrosion wear is a mixed potential reflecting the states of both the unworn surface and worn surface. Therefore, a galvanic coupling between the worn and unworn areas takes place. The OCP value depends on the following parameters: (1) the potential of the metals in the worn and unworn areas, (2) the area ratios of the worn and unworn surfaces, (3) the relative positions of the worn and unworn areas, and (4) the mechanism and kinetics of the anodic and cathodic reactions. ${ }^{25,26}$

The evolutions of OCP for TC4, 316 stainless steel, and Monel K500 are shown in Fig. 3. It can be observed that at the start of the corrosion wear, OCP sharply dropped to a more negative value. The similar cathodic shift phenomenon during the corrosion wear has been observed in other passive metallic materials at different corrosion wear systems., ${ }^{10,26,27}$ Passive oxide film on the metal surface is mechanically destroyed or partially removed by sliding. ${ }^{25,28}$ Active surface can increase the anodic reaction, and the released electrons cathodically polarize the surrounding surface. Therefore, OCP shifts towards the cathodic direction. A relative steady state is reached in potential owing to the establishment of an equilibrium level between mechanical depassivation and electrochemical repassivation rates. When friction stops, OCP starts to abruptly increase (anodic shift). This indicates the re-establishment of the passive state in the worn area. ${ }^{25}$

The polarization curves of TC4, 316 stainless steel, and Monel K500 under both corrosion-only and corrosion wear conditions are shown Fig. 4. The aim of corrosion-only test was to investigate the chemical stability of the passive film without any mechanical damage. Typical passivation phenomenon can be clearly observed for the three alloys. Polarization curves during corrosion wear can analyze corrosion and repassivating ability when the passive film is mechanically destroyed. However, the weak point of this method is the unsteady state of the electrochemical test system, which results in significant oscillations of the current data. Moreover, the contact positions

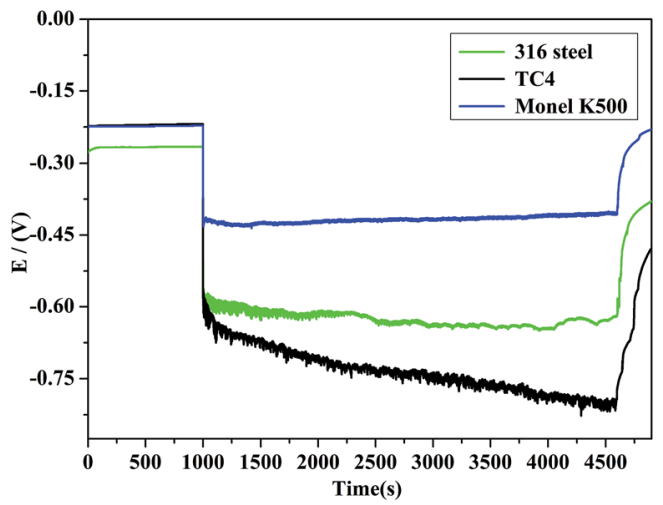

Fig. 3 The evolution of open circuit potential as a function of time.

of the pin-ring system continuously change, which contributes to the oscillations and instabilities of the polarization curves. ${ }^{29}$ The polarization curves of the three alloys during corrosion wear shown in Fig. 4 exhibit clear current oscillations. As the contact area of the friction couple is constant, the calculation of the corrosion current density is based on the area of the wear track. It can be seen that friction obviously affects the shape and position of the potentiodynamic polarization curves with respect to the corrosion-only reference curves. Table 2 presents the values of the corrosion potential $E$, corrosion current density $i_{\mathrm{t}}, i_{\mathrm{c}}$, and the ratio of $i_{\mathrm{t}} / i_{\mathrm{c}}$. The corrosion current during corrosion wear is much higher than that under the corrosiononly condition. This indicates that a rapid dissolution occurs in the worn surface. The $i_{\mathrm{t}} / i_{\mathrm{c}}$ value was calculated to explain the effect of wear on corrosion. The $i_{\mathrm{t}} / i_{\mathrm{c}}$ values indicated that the effect of wear on corrosion for TC4 was more significant than that for 316 stainless steel and Monel K500. In addition, Monel K500 exhibited a much lower corrosion current compared to that of 316 stainless steel and TC4. Low wear-acceleratedcorrosion effect occurred for Monel K500, which may be the reason for its low OCP value, as shown in Fig. $3 .^{26}$

In the potentiostatic polarization test, the applied cathodic potentials were $-0.9 \mathrm{~V},-0.8 \mathrm{~V}$, and $-0.6 \mathrm{~V}$ for TC4, 316 stainless steel, and Monel K500, respectively, and the applied anodic potentials were $0.2 \mathrm{~V},-0.2 \mathrm{~V}$, and $0.1 \mathrm{~V}$ for TC4, 316 stainless
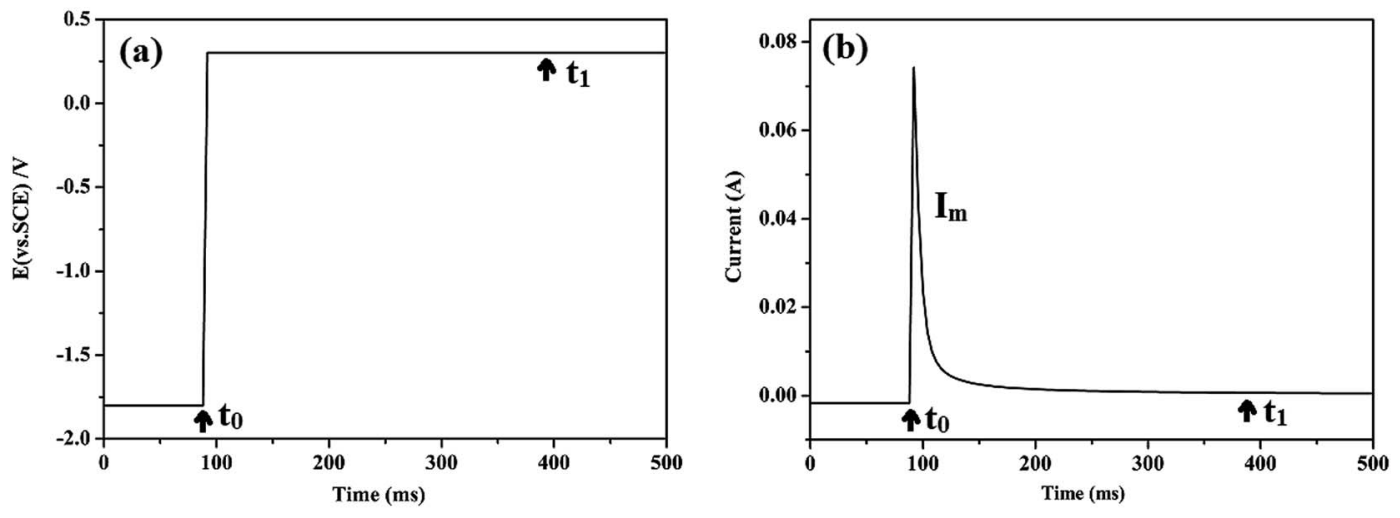

Fig. 2 An example of the change in potential and current of PPM method: (a) variation of potential and (b) variation of current. 
(a)

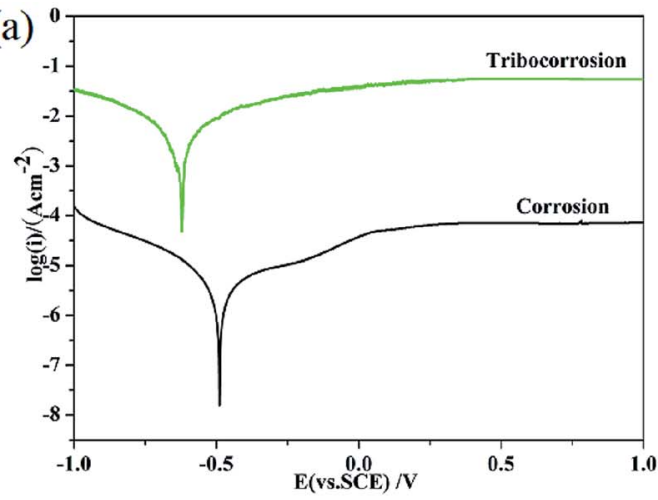

(b)

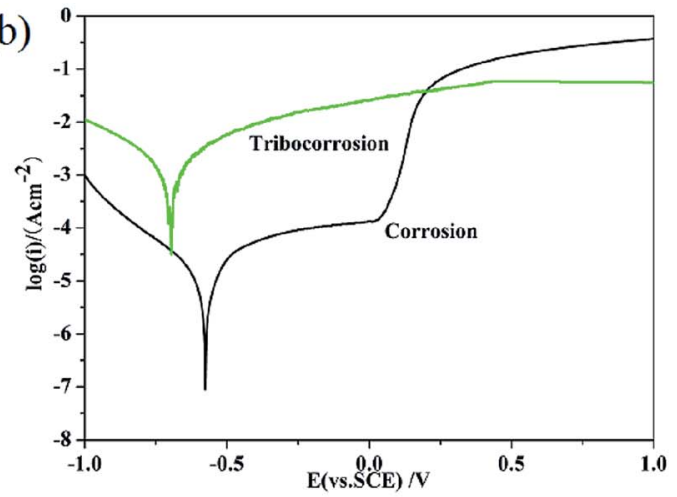

(c)

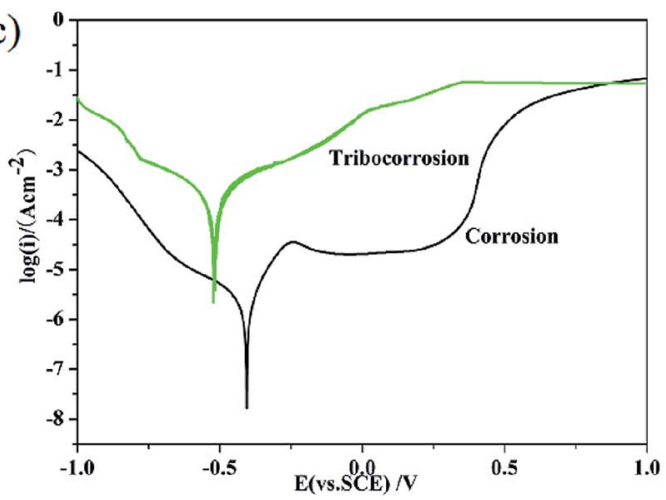

Fig. 4 The polarization curves under corrosion-only and corrosion wear conditions: (a) TC4; (b) 316 stainless steel; and (c) Monel K500.

Table 2 The values of $E, i$ and $i_{\mathrm{t}} / i_{\mathrm{c}}$ for the three alloys in corrosion-only and tribocorrosion conditions

\begin{tabular}{|c|c|c|c|c|c|}
\hline \multirow[b]{2}{*}{ Materials } & \multicolumn{2}{|c|}{ Corrosion-only } & \multicolumn{2}{|c|}{ Tribocorrosion } & \multirow[b]{2}{*}{$i_{\mathrm{t}} i_{\mathrm{c}}$} \\
\hline & $i_{\mathrm{c}}\left(\mu \mathrm{A} \mathrm{cm}^{-2}\right)$ & $E(\mathrm{~V})$ & $i_{\mathrm{t}}\left(\mu \mathrm{A} \mathrm{cm} \mathrm{cm}^{-2}\right)$ & $E(\mathrm{~V})$ & \\
\hline TC4 & 1.86 & -0.497 & 317 & -0.627 & 170.4 \\
\hline 316 stainless steel & 10.89 & -0.625 & 192 & -0.712 & 17.6 \\
\hline Monel K500 & 2.44 & -0.396 & 38.4 & -0.562 & 15.7 \\
\hline
\end{tabular}

steel, and Monel K500, respectively. The anodic potential was selected to maintain the alloys in a passive state. ,26,30 $^{2,30}$

Fig. 5 exhibits the evolution of the current density under cathodic and anodic polarization conditions during corrosion wear. It can be observed that the measured currents were cathodic (negative) before, during, and after sliding under cathodic polarization conditions for the three alloys, confirming that no corrosion occurred. Clearly, under this cathodic condition, material loss was only caused by pure mechanical wear. ${ }^{\mathbf{1 0 , 2 6 , 2 7}}$ At anodic potential, the current sharply increased at the beginning of sliding. The current curves exhibit significant oscillations, demonstrating the unsteady state of the electrochemical test system. TC4 and 316 stainless steel exhibit large corrosion currents as compared to Monel K500 under anodic conditions. Mechanical wear leads to thinning or local removal of the passive film, which subsequently repairs itself by oxidation of the metals. As a consequence, corrosion wear leads to a sharp increase of anodic current. The cyclic abrasion maintains the current at relatively high values. After corrosion wear stops, the current decreases again to a lower value. It proves that the current change is indeed caused by mechanical wear.

\subsection{Friction and wear}

Fig. 6 shows wear loss under cathodic polarization, OCP, and anodic polarization conditions for the three alloys. It is evident that wear loss at the cathodic potential is lower than that at the anodic potential and OCP. During cathodic polarization, the dissolution of metal ions was negligible, and the material loss was mainly through mechanical wear. Wear loss at the anodic potential was higher than that at OCP. The wear loss of 316 stainless steel was much larger than that for TC4 and Monel K500. Clearly, corrosion has a significant effect on material loss, as has been discussed in the next section. Similar results have been observed for many alloys under the corrosion wear condition. ${ }^{16,31-34}$

The evolution of friction coefficient with time is shown in Fig. 7 for the three alloys. Friction coefficient rapidly reached a steady state, exhibiting significant peaks at fairly regular time intervals. These fluctuations are attributed to the formation and ejection of wear debris as well as the uneven wear surface. ${ }^{35}$ Friction coefficient was apparently large at cathodic polarization. When corrosion takes place, this leads to an increase in the surface roughness and, consequently, a reduction in the contact area. ${ }^{31}$ Moreover, 316 stainless steel 

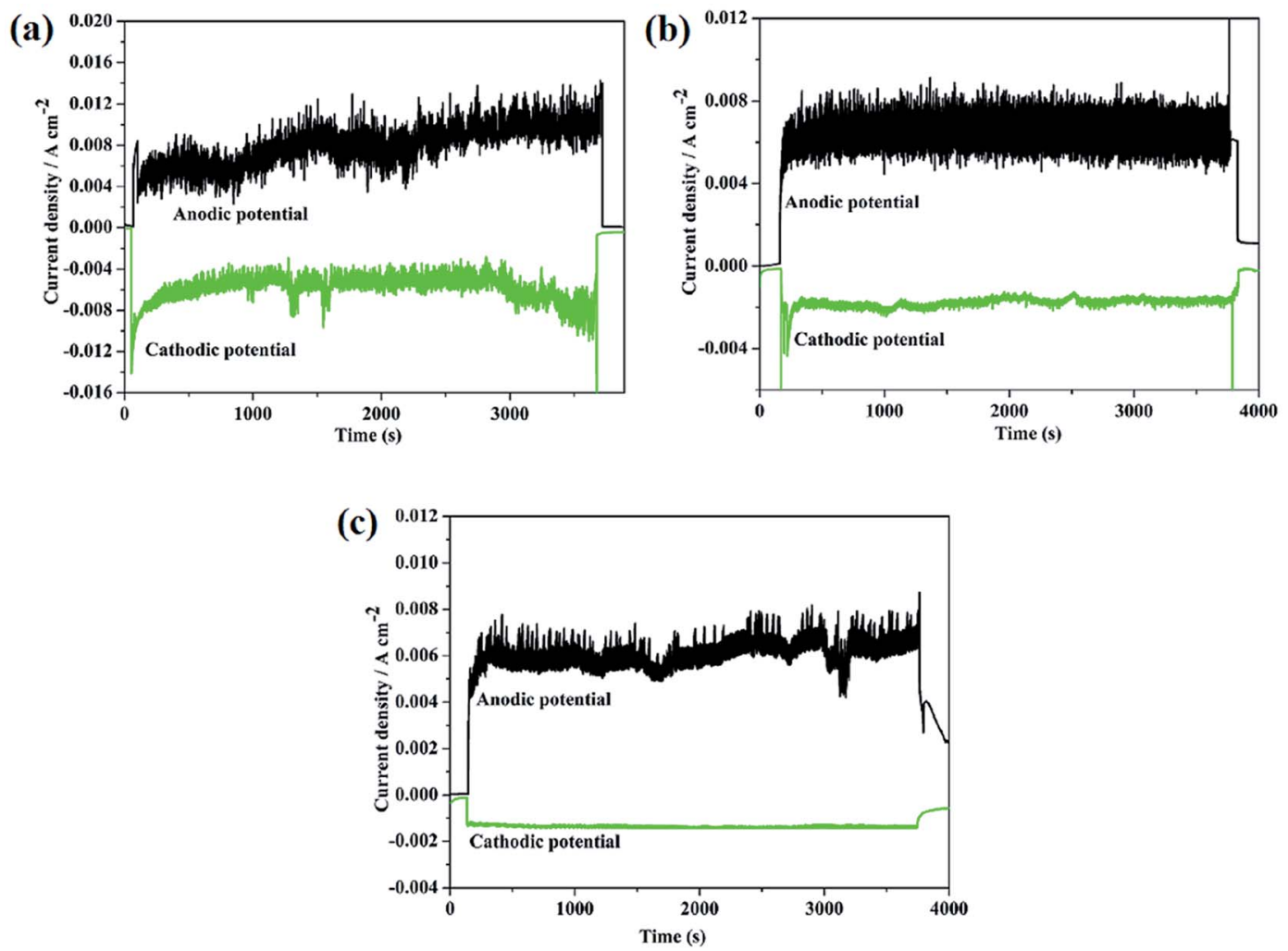

Fig. 5 The evolution of the current density under cathodic and anodic polarization conditions: (a) TC4; (b) 316 stainless steel; and (c) Monel K500.

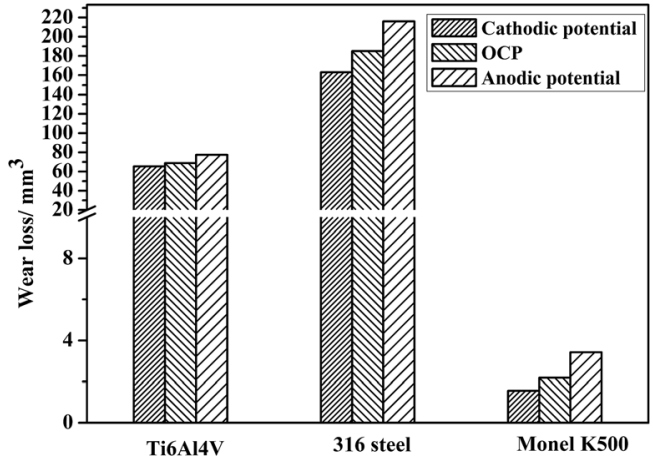

Fig. 6 The wear volume loss for the three alloys.

exhibits a large friction coefficient compared with TC4 and Monel K500.

\subsection{Material degradation}

In addition to the commonly observed phenomena during corrosion wear related to the cathodic shift of OCP, the increase of anodic current, and the accelerated wear loss, the synergism between corrosion and wear and the accelerated wear loss caused by anodic potential need to be further discussed. The wear loss obtained at cathodic potential can be regarded as pure mechanical wear. The results summarized in Fig. 6 clearly show that high wear loss is obtained when corrosion occurs, either under OCP or anodic potential conditions. Polarization curves (Fig. 4) and corrosion current measurements (Fig. 5) show the increase in corrosion current during corrosion wear. There are significant synergistic effects between corrosion and wear, resulting in corrosion-induced wear and wear-induced corrosion. Efforts have been made to quantify this synergistic effect using the following general approach..$^{\mathbf{1 0 1 8 , 3 6 - 3 8}}$ The wear loss data can be explained by defining the following terms:

$$
K_{\mathrm{wc}}=K_{\mathrm{c}}+K_{\mathrm{w}}=K_{\mathrm{wo}}+\Delta K_{\mathrm{w}}+K_{\mathrm{co}}+\Delta K_{\mathrm{c}}
$$

where $K_{\mathrm{wc}}$ is the total wear loss, $K_{\mathrm{w}}$ is the wear loss induced by wear, and $K_{\mathrm{c}}$ is the wear loss induced by corrosion. $K_{\mathrm{wo}}$ is pure wear loss without corrosion, which can be estimated by measuring at cathodic potential. $\Delta K_{\mathrm{w}}$ is wear loss caused by the effect of corrosion on wear. $K_{\text {co }}$ is wear loss induced by corrosion without wear, and $\Delta K_{\mathrm{c}}$ is wear loss caused by the effect of wear on corrosion or the enhancement of corrosion induced by wear. Material loss $K$ caused by corrosion including values of $K_{\text {co }}$ and $K_{\mathrm{c}}$ can be obtained by Faraday's equation.

The results of various contributions to total material loss are given in Table 3 . Note that the contribution of $K_{\text {co }}$ to total material loss for the three alloys is very small, indicating the negligible effect of pure corrosion. Overall, pure mechanical wear and synergistic effect between wear and corrosion are dominating factors. Fig. 8 shows the specific values of $K_{\mathrm{c}} / K_{\mathrm{w}}$, $\Delta K_{\mathrm{c}} / K_{\mathrm{c}}$, and $\Delta K_{\mathrm{w}} / K_{\mathrm{w}}$. It can be noticed that wear $\left(K_{\mathrm{w}}\right)$ is 

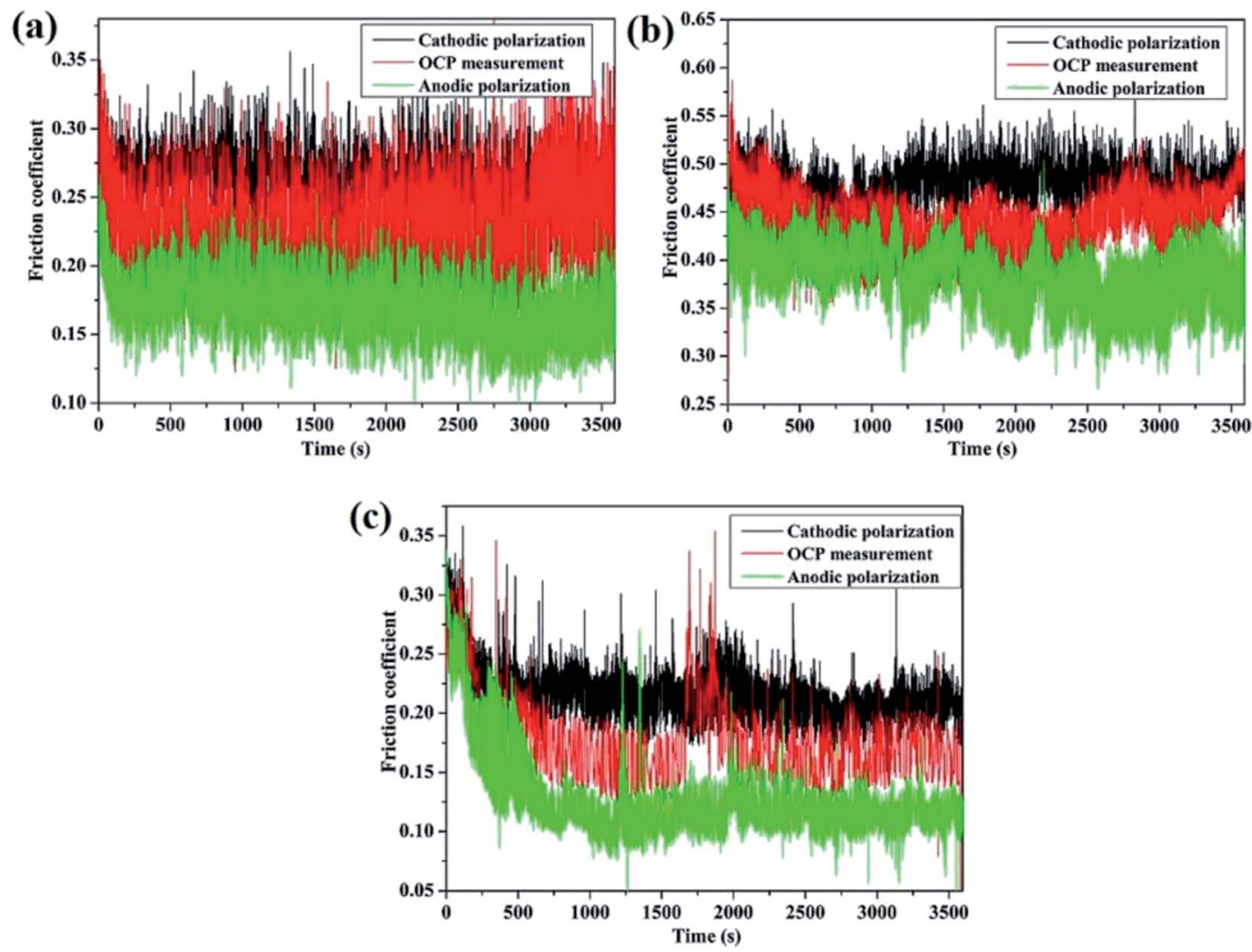

Fig. 7 The evolution of COF at different electrochemical conditions: (a) TC4; (b) 316 stainless steel; and (c) Monel K500.

dominant for the three alloys, and the value of $K_{\mathrm{c}} / K_{\mathrm{w}}$ is high under anodic conditions compared with that under OCP conditions. The proportion of $K_{\mathrm{c}}$ in wear loss for Monel K500 is higher than that for 316 stainless steel and TC4. Obviously, wear loss caused by corrosion is almost equivalent to the wearinduced corrosion. The values of $\Delta K_{\mathrm{w}} / K_{\mathrm{w}}$ are in the range of $20-40 \%$ for the three alloys.

Wear-induced corrosion and corrosion-induced wear play a dominant role in material loss. Fig. 9 shows the fraction of $\Delta K_{\mathrm{c}}, \Delta K_{\mathrm{w}}$, and $K_{\mathrm{wo}}$ for the three alloys. Note that relative contribution of pure wear to total material loss is in the range of $45-72 \%$. Moreover, the contribution of pure wear to total wear loss is high under OCP compared with that under anodic conditions, indicating that corrosion plays a great role in the material loss especially at high potential. Importantly, the contributions of wear-induced corrosion and corrosion-induced wear are very important, especially for Monel K500 at anodic potential. Note that although the electrochemical dissolution is significantly promoted and corrosion rate is highly increased due to sliding, the contribution of $\Delta K_{\mathrm{c}}$ to total material loss is not very large. Actually, it is in the range of $0.92-6.29 \%$ for 316 stainless steel and TC4. Moreover, it is not more than $20 \%$ for Monel K500. On the contrary, the ratio of corrosion-induced wear to total wear loss is very large, and it is in the range of $16.9-35.2 \%$. The results obtained in this present study show that the ratio of wear-accelerated corrosion to the total wear loss is small, and pure mechanical and corrosion-induced wear are dominant factors during corrosion wear.

Fig. 10 shows the typical images for the three alloys. It can be seen that these alloys exhibit different wear mechanisms. The worn surfaces of TC4 and Monel K500 are characterized by mainly flat regions interrupted by furrows parallel to the sliding direction. The worn surfaces of 316 stainless steel are dominated by sharp ridges and thin flakes. ${ }^{29,30}$ Moreover, the

Table 3 The results of various contributions to total volume loss

\begin{tabular}{lllllllll}
\hline Potential & Materials & $K_{\mathrm{wc}}\left(\mathrm{mm}^{3}\right)$ & $K_{\mathrm{w}}\left(\mathrm{mm}^{3}\right)$ & $K_{\mathrm{c}}\left(\mathrm{mm}^{3}\right)$ & $K_{\mathrm{wo}}\left(\mathrm{mm}^{3}\right)$ & $\Delta K_{\mathrm{w}}\left(\mathrm{mm}^{3}\right)$ & $K_{\mathrm{co}}\left(\mathrm{mm}^{3}\right)$ & $\Delta K_{\mathrm{c}}\left(\mathrm{mm}^{3}\right)$ \\
\hline \multirow{2}{*}{ OCP } & 316 & 185 & 183.3 & 1.7 & 134.8 & 48.5 & 0.0049 \\
& TC4 & 68.7 & 66.5 & 2.23 & 43.8 & 22.7 & 1.7 \\
\multirow{4}{*}{ Anodic potential } & Monel K500 & 2.18 & 1.93 & 0.25 & 1.56 & 0.37 & 0.031 \\
& 316 & 216 & 210.8 & 5.2 & 134.8 & 76 & 0.0025 & 0.25 \\
& TC4 & 77.4 & 72.5 & 4.9 & 43.8 & 28.7 & 0.023 \\
& Monel K500 & 3.42 & 2.76 & 0.66 & 1.56 & 1.2 & 4.18 \\
\end{tabular}




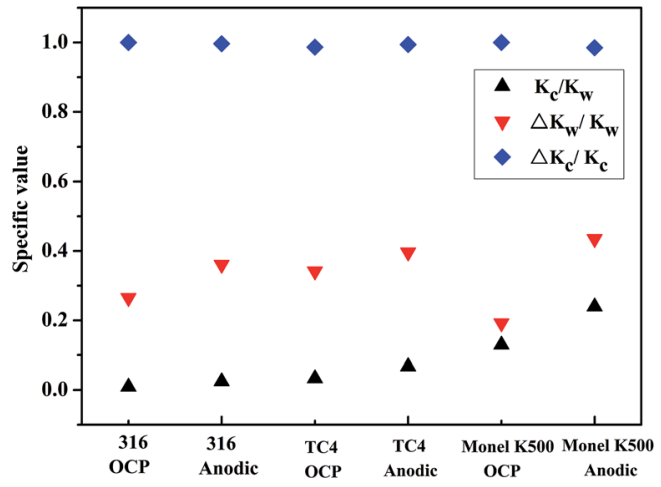

Fig. 8 The special values of $K_{c} / K_{w}, \Delta K_{c} / K_{c}$, and $\Delta K_{w} / K_{w}$.

electrochemical state may affect the deterioration mechanism and surface morphology. At the cathodic potential, the wear track is generally very smooth and featureless, except for some isolated furrows for TC4 and Monel K500 and some ridges and thin flakes for 316 stainless steel. At OCP and anodic potential, the worn surfaces exhibit typical deformation features. These images also show some wear debris. (a)
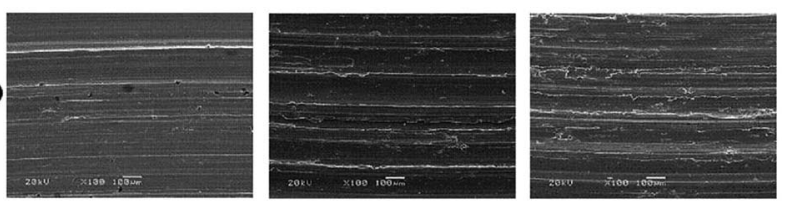

(b)
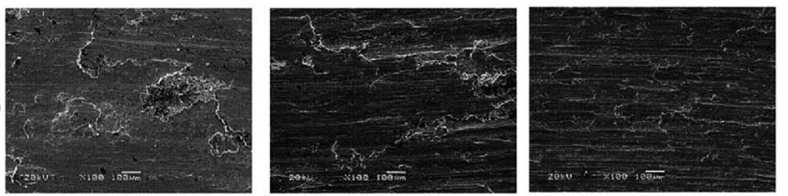

(c)

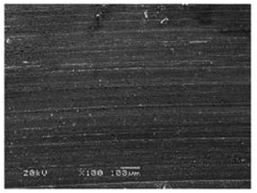

Cathodic

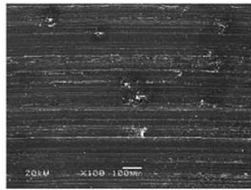

OCP

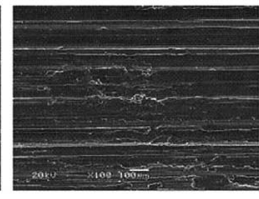

Anodic

Fig. 10 The typical images of the wear surface: (a) TC4; (b) 316 stainless steel; and (c) Monel K500.

\subsection{Passive film failure mechanism}

Passive film can be damaged due to wear, resulting in low OCP and high corrosion rate. The damage-recovery process of the
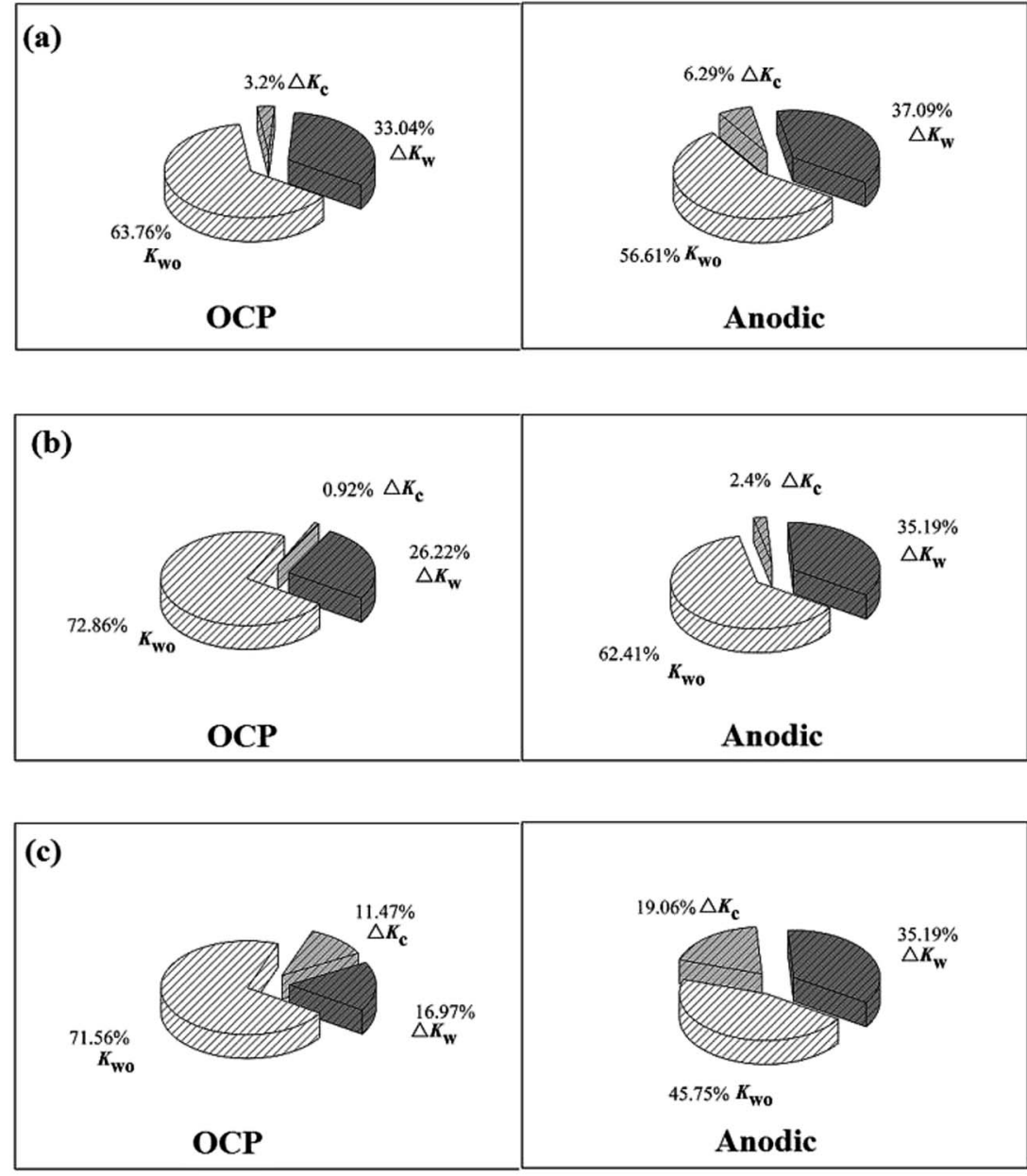

Fig. 9 The fractions of $\Delta K_{\mathrm{c}}, \Delta K_{\mathrm{w}}$, and $K_{\mathrm{wo}}$ : (a) TC4; (b) 316 stainless steel; and (c) Monel K500. 
passive film and formation of a fresh surface is an important field for corrosion wear research. For simulating the damagerecovery process of the passive film and evaluating the destruction proportion of the passive film, potential pulse method (PPM) was used in this research, as shown in Fig. 2. The applied cathodic potentials were $-0.9 \mathrm{~V},-0.8 \mathrm{~V}$, and $-0.6 \mathrm{~V}$ for TC4, 316 stainless steel, and Monel K500, respectively. The given OCP potentials were $-0.22 \mathrm{~V},-0.23 \mathrm{~V}$, and $-0.26 \mathrm{~V}$ for TC4, 316 stainless steel, and Monel K500, respectively, and the given anodic potentials were $0.2 \mathrm{~V},-0.2 \mathrm{~V}$, and $0.1 \mathrm{~V}$ for TC4, 316 stainless steel, and Monel K500, respectively. The evolutions of the currents are shown in Fig. 11. It can be seen that the values of the currents are negative at cathodic potential, indicating the disappearance of the passive film and the formation of a fresh film. When the applied potential instantaneously changed from cathodic potential to a given potential, the current sharply increased in a moment, then quickly decreased, and finally stabilized at a low positive current value. This electrochemical variation procedure can simulate the passivation process of the fresh film. The evolution of current exhibits the corrosion kinetics of the re-establishment of the passive state.

The variation extent of the corrosion current is very large, as shown in Fig. 11, and this causes much difficulty in the quantitative analysis. Therefore, the concept of the electricity value $Q$ and average current density $I_{\mathrm{pm}}$ was introduced to evaluate the passivation process. The electricity charge $Q$ can be defined as follows:
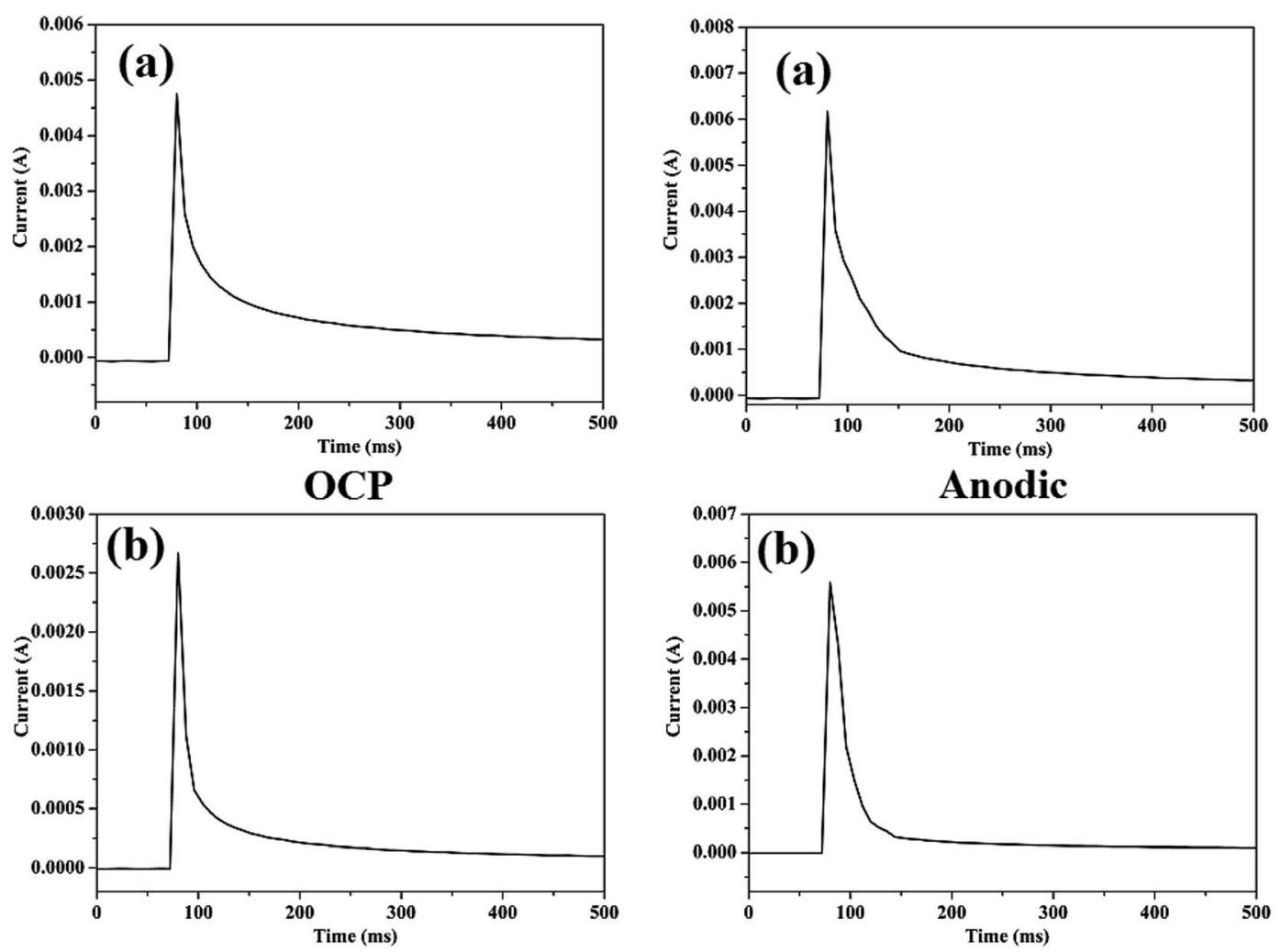

OCP
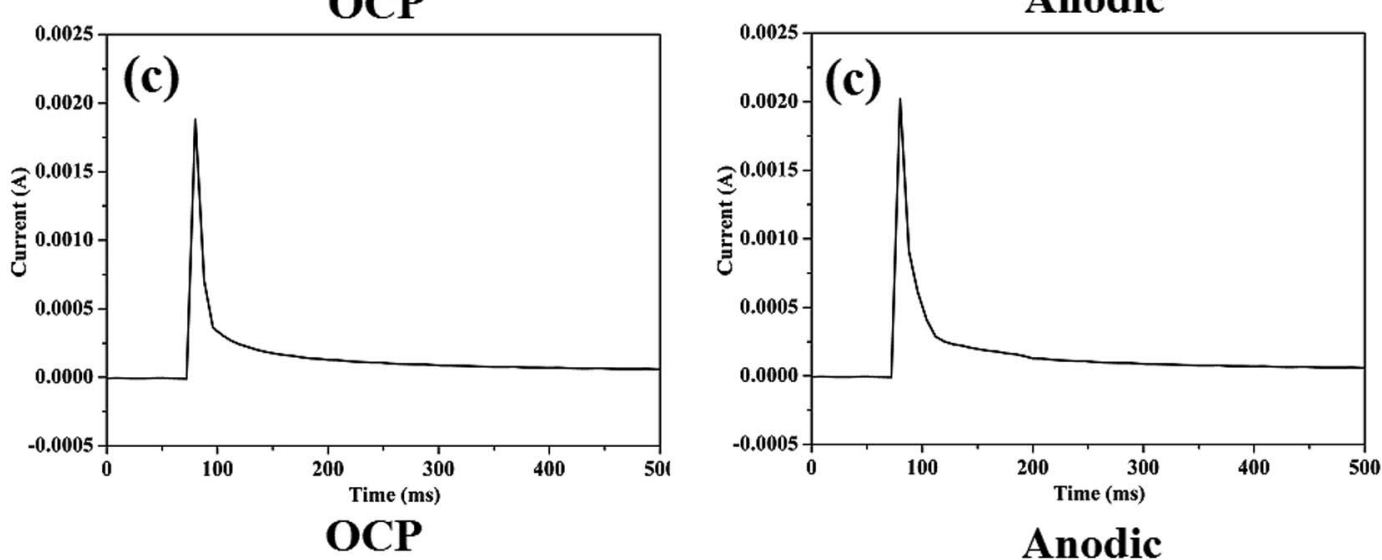

Fig. 11 The evolution of current during PPM test: (a) TC4; (b) 316 stainless steel; and (c) Monel K500. 
Table 4 The results of various corrosion parameters of the three alloys by PPM electrochemical approach

\begin{tabular}{|c|c|c|c|c|c|c|}
\hline Alloy & $\begin{array}{l}\text { Electrochemical } \\
\text { condition }\end{array}$ & $I_{\mathrm{pm}}\left(\mathrm{mA} \mathrm{cm}^{-2}\right)$ & $\begin{array}{l}I \\
\left(\mathrm{~mA} \mathrm{~cm}^{-2}\right)\end{array}$ & $S_{\mathrm{m}}\left(\mathrm{cm}^{2}\right)$ & $S_{\mathrm{e}}\left(\mathrm{cm}^{2}\right)$ & $S_{\mathrm{e}} / S_{\mathrm{m}}$ \\
\hline TC4 & OCP & 4.75 & 3.17 & 8 & 5.34 & $66.7 \%$ \\
\hline \multirow[t]{2}{*}{316} & OCP & 2.67 & 1.92 & 8 & 5.75 & $71.9 \%$ \\
\hline & Anodic & 6.18 & 5.38 & 8 & 6.96 & $87.1 \%$ \\
\hline Monel K500 & OCP & 1.88 & 0.26 & 8 & 1.11 & $13.8 \%$ \\
\hline
\end{tabular}

$$
Q=\int_{t_{0}}^{t_{1}} I_{m} \mathrm{~d} t
$$

where $I_{\mathrm{m}}$ is the evolution of corrosion current during the PPM test, as shown in Fig. 11. For a combination of the PPM method and corrosion wear process, the recovery time of the passive film should be equal to a friction period. Thus, $t_{0}$ and $t_{1}$ are the start and end times of a friction cycle, respectively. The friction test period $T$ is $300 \mathrm{~ms}$ in this experiment. The average current density $I_{\mathrm{pm}}$ of the passive film in a worn area can be expressed as follows:

$$
I_{\mathrm{pm}}=\frac{Q}{T}
$$

For a special corrosion wear process, the passive film in a wear scan area may not be completely damaged. Therefore, the actual breakdown area of the passive film $S_{\mathrm{e}}$ can be derived by the following formula.

$$
S_{\mathrm{e}}=\frac{I \times S_{\mathrm{m}}}{I_{\mathrm{pm}}}
$$

where $I$ is the corrosion current obtained from potentiodynamic and potentiostatic polarization. The area of the wear track $S_{\mathrm{m}}$ has a fixed value of $8 \mathrm{~cm}^{2}$.

The results of various corrosion parameters using the PPM approach are given in Table 4 . It can be observed that the average current density $I_{\mathrm{pm}}$ is obviously higher than the in situ measured corrosion current density I, indicating that passive film in the wear track is only partially destroyed in this experiment. Considering the actual damage area of the passive film $S_{\mathrm{e}}$, the three alloys exhibited different trends. The ratio of the actual damage area $S_{\mathrm{e}} / S_{\mathrm{m}}$ for 316 stainless steel and TC4 was very large. This was $66.7 \%$ and $71.9 \%$ at OCP and $88.1 \%$ and $87.1 \%$ at anodic polarization. However, the values of $S_{\mathrm{e}} / S_{\mathrm{m}}$ for Monel $\mathrm{K} 500$ were relatively small. It was only $13.8 \%$ at OCP and $21.9 \%$ at anodic polarization. It indicates that the passive film of Monel K500 exhibits high resistance to sliding damage compared with 316 stainless steel and TC4. More importantly, the electrochemical state had a significant influence on the destruction proportion of the passive film during corrosion wear, and the actual damage area of the passive film $S_{\mathrm{e}}$ was high under the anodic conditions than that under the OCP conditions for the three alloys.

\section{Conclusions}

Based on the results obtained in the present study, several conclusions can be drawn regarding the corrosion wear behavior of the three alloys in artificial seawater under sliding contact with an alumina pin. Specifically, the contribution of corrosion and wear to synergism and the damage-recovery process of the passive film were addressed.

(1) The cathodic shift of OCP was confirmed, and the current density was obviously increased during corrosion wear for the three alloys.

(2) The wear loss for the three alloys at cathodic potential was lower than that at OCP and anodic potential. The wear loss of 316 stainless steel was much larger than that measured for TC4 and Monel K500. Friction coefficients were apparently large in cathodic polarization compared with those in anodic polarization.

(3) The contribution of pure corrosion to total material loss for three alloys was very small. Considering the synergy between wear and corrosion, the ratio of wear-accelerated corrosion to the total wear loss was small. Pure wear and corrosion-induced wear were dominant during corrosion wear.

(4) The passive film in the wear track was only partially destroyed in this experiment. The ratios of the actual damage area $S_{\mathrm{e}} / S_{\mathrm{m}}$ for 316 stainless steel and TC4 were much larger than that for Monel K500. The actual damage area of the passive film $S_{\mathrm{e}}$ was high under anodic conditions compared with that under OCP conditions for the three alloys.

\section{Acknowledgements}

The research was financially supported by the National Natural Science Foundation of China (Grant No. U1604130 and 51675162).

\section{References}

1 E. Boese, J. Rothig, I. Garz, et al., Tribocorrosion of stainless steels, Mater. Corros., 1998, 49, 98-107.

2 S. W. Watson, F. J. Friedersdorf, B. W. Madsen, et al., Methods of measuring wear corrosion synergism, Wear, 1995, 181, 476-484.

3 Y. Zhang, X. Yin, J. Wang, et al., Influence of potentials on the tribocorrosion behavior of 304SS in artificial seawater, RSC Adv., 2014, 4, 55752-55759. 
4 D. Landolt, S. Mischler and M. Stemp, Electrochemical methods in tribocorrosion: a critical appraisal, Electrochim. Acta, 2001, 46, 3913-3929.

5 J. R. Goldberg and J. L. Gilbert, Electrochemical response of CoCrMo to high-speed fracture of its metal oxide using an electrochemical scratch test method, J. Biomed. Mater. Res., 1997, 37, 421-431.

6 J. O. Bello, R. J. K. Wood and J. A. Wharton, Synergistic effects of micro-abrasion-corrosion of UNS S30403, S31603 and S32760 stainless steels, Wear, 2007, 263, 149-159.

7 S. Mischler and a I. Muñoz, Wear of CoCrMo alloys used in metal-on-metal hip joints: A tribocorrosion appraisal, Wear, 2013, 297, 1081-1094.

8 I. García, D. Drees and J. P. Celis, Corrosion-wear of passivating materials in sliding contacts based on a concept of active wear track area, Wear, 2001, 249, 452460.

9 A. Iwabuchi, T. Tsukamoto, T. Shimizu, et al., The mechanism of corrosive wear of an austenitic stainless steel in an aqueous electrolyte solution, Tribol. Trans., 1998, 41, 96-102.

10 A. Iwabuchi, J. W. Lee and M. Uchidate, Synergistic effect of fretting wear and sliding wear of Co-alloy and Ti-alloy in Hanks' solution, Wear, 2007, 263, 492-500.

11 A. Iwabuchi, T. Sonoda, H. Yashiro, et al., Application of potential pulse method to the corrosion behavior of the fresh surface formed by scratching and sliding in corrosive wear, Wear, 1999, 225-229, 181-189.

12 A. Iwabuchi, T. Tsukamoto, Y. Tatsuyanagi, et al., Electrochemical approach to corrosive wear of SKD61 die steel in $\mathrm{Na}_{2} \mathrm{SO}_{4}$ solution, Wear, 1992, 156, 301-313.

$13 \mathrm{~J}$. W. Li, A. Iwabuchi, T. Shimizu, et al., A study on the fretting wear of SUS304 steel in $\mathrm{Na}_{2} \mathrm{SO}_{4}$ solution, J. Jpn. Soc. Tribol., 2005, 50, 180-186.

14 P. Jemmely, S. Mischler and D. Landolt, Electrochemical modeling of passivation phenomena in tribocorrosion, Wear, 2000, 237, 63-76.

15 C. O. A. Olsson and M. Stemp, Modelling the transient current from two rubbing electrode configurations: insulating pin on metal substrate and metal pin on insulating substrate, Electrochim. Acta, 2004, 49, 2145-2154.

16 P. Henry, J. Takadoum and P. Berçot, Tribocorrosion of 316L stainless steel and TA6V4 alloy in $\mathrm{H}_{2} \mathrm{SO}_{4}$ media, Corros. Sci., 2009, 51, 1308-1314.

17 P. Henry, J. Takadoum and P. Bercot, Depassivation of some metals by sliding friction, Corros. Sci., 2011, 53, 320-328.

18 M. M. Stack, J. Rodling, M. T. Mathew, et al., Micro-abrasioncorrosion of a Co-Cr/UHMWPE couple in Ringer's solution: An approach to construction of mechanism and synergism maps for application to bio-implants, Wear, 2010, 269, 376-382.

19 R. Alonso Gil and A. Igual Munoz, Influence of the sliding velocity and the applied potential on the corrosion and wear behavior of HC CoCrMo biomedical alloy in simulated body fluids, J. Mech. Behav. Biomed. Mater., 2011, 4, 2090-2102.
20 N. Espallargas, R. Johnsen, C. Torres, et al., A new experimental technique for quantifying the galvanic coupling effects on stainless steel during tribocorrosion under equilibrium conditions, Wear, 2013, 307, 190-197.

21 J. Liu, X. Wang, B. J. Wu, et al., Tribocorrosion behavior of DLC-coated CoCrMo alloy in simulated biological environment, Vacuum, 2013, 92, 39-43.

22 X. Li, Q. Zhang, Z. Guo, et al., Fabrication of superhydrophobic surface with improved corrosion inhibition on 6061 aluminum alloy substrate, Appl. Surf. Sci., 2015, 342, 76-83.

23 X. Li, T. Shi, C. Liu, et al., Multifunctional substrate of Al alloy based on general hierarchical micro/nanostructures: superamphiphobicity and enhanced corrosion resistance, Sci. Rep., 2016, 6, 1-10.

24 N. Espallargas and S. Mischler, Tribocorrosion behaviour of overlay welded Ni-Cr 625 alloy in sulphuric and nitric acids: Electrochemical and chemical effects, Tribol. Int., 2010, 43, 1209-1217.

25 P. Ponthiaux, F. Wenger, D. Drees, et al., Electrochemical techniques for studying tribocorrosion processes, Wear, 2004, 256, 459-468.

26 K. C. Tekin and U. Malayoglu, Assessing the Tribocorrosion Performance of Three Different Nickel-Based Superalloys, Tribol. Lett., 2010, 37, 563-572.

27 Y. Sun and V. Rana, Tribocorrosion behaviour of AISI 304 stainless steel in $0.5 \mathrm{M} \mathrm{NaCl}$ solution, Mater. Chem. Phys., 2011, 129, 138-147.

28 N. Diomidis, J. P. Celis, P. Ponthiaux, et al., Tribocorrosion of stainless steel in sulfuric acid: Identification of corrosion-wear components and effect of contact area, Wear, 2010, 269, 93-103.

29 M. Salasi, G. B. Stachowiak and G. W. Stachowiak, New Experimental Rig to Investigate Abrasive-Corrosive Characteristics of Metals in Aqueous Media, Tribol. Lett., 2010, 40, 71-84.

30 S. Akonko, D. Y. Li and M. Ziomek-Moroz, Effects of cathodic protection on corrosive wear of 304 stainless steel, Tribol. Lett., 2005, 18, 405-410.

31 a I. Munoz and L. C. Julian, Influence of electrochemical potential on the tribocorrosion behaviour of high carbon CoCrMo biomedical alloy in simulated body fluids by electrochemical impedance spectroscopy, Electrochim. Acta, 2010, 55, 5428-5439.

32 N. Espallargas and S. Mischler, Tribocorrosion behaviour of overlay welded Ni-Cr 625 alloy in sulphuric and nitric acids: Electrochemical and chemical effects, Tribol. Int., 2010, 43, 1209-1217.

33 I. Serre, N. Celati and R. M. Pradeilles-Duval, Tribological and corrosion wear of graphite ring against Ti6Al4V disk in artificial sea water, Wear, 2002, 252, 711-718.

34 S. Barril, S. Mischler and D. Landolt, Electrochemical effects on the fretting corrosion behaviour of Ti6Al4V in $0.9 \%$ sodium chloride solution, Wear, 2004, 259, 282-291. 
35 S. Mischler, A. Spiegel, M. Stemp, et al., Influence of passivity on the tribocorrosion of carbon steel in aqueous solutions, Wear, 2001, 251, 1295-1307.

36 J. Jiang, M. M. Stack and A. Neville, Modelling the tribocorrosion interaction in aqueous sliding conditions, Tribol. Int., 2002, 35, 669-679.
37 S. Mischler, Triboelectrochemical techniques and interpretation methods in tribocorrosion: A comparative evaluation, Tribol. Int., 2008, 41, 573-583.

38 S. W. Watson, F. J. Friedersdorf, B. W. Madsen, et al., Methods of Measuring Wear Corrosion Synergism, Wear, 1995, 181, 476-484. 